\title{
Análise de Atividades Gráficas para Crianças com Síndrome de Down ${ }^{1}$ Analysis of GRAPHIC ACTIVITIES FOR CHILDREN WITH DOWN SyNDROME
}

\author{
Agnes Lara Eringer BORGES ${ }^{2}$ \\ Miryam Bonadiu PELOSI ${ }^{3}$ \\ Janaína Santos NASCIMENTO ${ }^{4}$ \\ Juliana Valéria de MELO5
}

\begin{abstract}
RESUMO: a educação inclusiva no Brasil é um direito da pessoa com deficiência e inclui o uso de recursos de Tecnologia Assistiva visando ampliar as habilidades funcionais dos estudantes, promover autonomia e participação. Dentre as áreas da Tecnologia Assistiva está o desenvolvimento de material escrito acessível, que tem papel fundamental na reduçâo de barreiras à aprendizagem de pessoas com deficiência. Considerando a importância do tema, o objetivo deste estudo foi analisar a acessibilidade das atividades gráficas aplicadas às crianças com síndrome de Down nos atendimentos terapêuticos ocupacionais, que ocorreram em uma Brinquedoteca Terapêutica, no período de um semestre. Para isso, foi realizada pesquisa aplicada, descritiva, com abordagem quantitativa, em que foram avaliadas 278 atividades utilizadas com 24 sujeitos, com idades entre 2 e 13 anos, a partir da criação de um protocolo. Os dados quantitativos foram verificados pelo software Statistical Package for The Social Sciences - SPSS, versão 19.0. Os resultados mostraram que os materiais gráficos estavam de acordo com as orientaçóes da literatura no que se refere à apresentação visual, à organização do conteúdo, ao nível de leitura e ao uso de elementos para transmitir informaçôes, mas os textos escritos com o apoio de símbolos precisavam ser aprimorados, assim como a inclusáo de elementos para direcionar o local da resposta e palavras-chave em destaque no enunciado. Concluiu-se que os materiais gráficos desenvolvidos pelos terapeutas ocupacionais estavam acessíveis para a populaçáo estudada, porém não foi possível verificar outros elementos referentes à aplicação da atividade que pudessem influenciar na acessibilidade.
\end{abstract}

PALAVRAS-CHAVE: Educação Especial. Tecnologia Assistiva. Terapia Ocupacional. Síndrome de Down. Educação dos Deficientes Intelectuais.

\begin{abstract}
Inclusive education in Brazil is a right of the person with disabilities and includes the use of Assistive Technology resources in order to expand the functional abilities of the students, promote autonomy and participation. Among the areas of Assistive Technology is the development of accessible written material, which has a fundamental role in reducing barriers to learning of people with disabilities. Considering the importance of the subject, the objective of this study was to analyze the accessibility of graphics activities applied to children with Down syndrome in occupational therapeutic care, which occurred in a therapeutic toy library for one semester. For this, an applied and descriptive research, with quantitative approach was carried out, in which 278 activities were evaluated using 24 subjects, aged between 2 and 13 years, from the creation of a protocol. Quantitative data have been checked by the software Statistical Package for The Social Sciences-SPSS, version 19.0. The results showed that the graphic materials were in accordance with the guidelines of the literature regarding visual presentation, content organization, reading level and the use of elements to transmit information, but the texts written with symbol support needed to be improved, as well as the inclusion of elements to direct the location of the answer and keywords highlighted in the statement. It was concluded that the graphic materials developed by the occupational therapists were accessible to the studied population, however it was not possible to verify other elements related to the application of the activity that could influence accessibility.
\end{abstract}

KEYWORDS: Special Education. Assistive Technology. Occupational Therapy. Down syndrome. Intellectual Disabled People Education.

\footnotetext{
${ }^{1}$ http://dx.doi.org/10.1590/S1413-65382317000400008

${ }^{2}$ Universidade Federal do Rio de Janeiro, Rio de Janeiro, RJ, Brasil. eringer.lara@gmail.com

${ }^{3}$ Docente do Departamento de Terapia Ocupacional/Faculdade de Medicina, Universidade Federal do Rio de Janeiro, Rio de Janeiro, RJ, Brasil. miryampelosi@ufrj.br

${ }^{4}$ Docente do Departamento de Terapia Ocupacional/Faculdade de Medicina, Universidade Federal do Rio de Janeiro, Rio de Janeiro, RJ, Brasil. jananascimento.to@gmail.com

${ }_{5}^{5}$ Docente do Departamento de Terapia Ocupacional/Faculdade de Medicina, Universidade Federal do Rio de Janeiro, Rio de Janeiro, RJ, Brasil. julianamelo_to@hotmail.com
} 


\section{INTRODUÇÃo}

A educação inclusiva no Brasil, em todos os níveis de ensino, é direito da pessoa com deficiência e inclui o uso de recursos, metodologias, estratégias e serviços de Tecnologia Assistiva, com o objetivo de ampliar as habilidades funcionais dos estudantes, promovendo sua autonomia e participação (BRASIL, 2015).

Nesse contexto estão as crianças com síndrome de Down, que apresentam alterações globais do desenvolvimento, com variaçóes da capacidade cognitiva, clínica e física. $\mathrm{Na}$ área cognitiva, manifestam-se como dificuldades de atenção, memória, processamento auditivo da informação, capacidade de correlação, análise e pensamento abstrato, além de outros comprometimentos nos aspectos clínicos e físicos (BISSOTO, 2005; SILVA; KLEINHANS, 2006).

Alunos com déficit intelectual apresentam problema em compreender conteúdos abstratos e demandam mais tempo para aquisição de conhecimento, mas podem ter este processo facilitado a partir do apoio de objetos, estratégias visuais e recursos acessíveis. É preciso identificar e eliminar as barreiras ao processo de aprendizagem, para favorecer seu desenvolvimento (MACEDO et al., 2009; SOUZA; GOMES, 2015).

Muitas dessas barreiras podem estar presentes no material gráfico ofertado a essa população, e, por essa razão, é fundamental identificar fatores que limitam a compreensão da mensagem transmitida graficamente, analisando seus elementos e verificando sua acessibilidade.

A literatura prevê normas e orientaçóes com essa finalidade. Descreve os aspectos que devem ser considerados e como os recursos visuais devem ser utilizados, organizados e apresentados para auxiliar a transmissão do conteúdo principal e estimular o interesse do leitor. Sabe-se que a compreensão é afetada pela legibilidade, aparência, organização da informação, objetividade e clareza (ABNT, 2004; CDC, 2009; BERGUER, 2011).

A norma da ABNT 9050:2004 sobre legibilidade e textos acessíveis é baseada no conceito de desenho universal, que consiste na concepção de produtos, ambientes, programas e serviços a serem usados por todas as pessoas, sem necessidade de adaptação ou de projeto específico, incluindo os recursos de Tecnologia Assistiva (BRASIL, 2015).

Recentemente, o conceito de desenho universal, originado na arquitetura, passou a ser utilizado em outras áreas, como na Educação (CALEGARI et al., 2014), e apresenta-se como uma via para democratizar o acesso aos materiais e serviços, considerando as necessidades específicas das pessoas. A norma da ABNT 15599:2008 complementa que na área da Educação deve ser ofertado um ambiente acolhedor, com recursos de Tecnologia Assistiva que promovam a acessibilidade ao conhecimento (ABNT, 2008).

A Convenção sobre os Direitos das Pessoas com Deficiência, assinada em março de 2007, afirma que os obstáculos físicos, atitudinais ou comportamentais devem ser identificados e eliminados para favorecer a acessibilidade e, conforme pactuado, cada um dos Estados Parte deve se responsabilizar pelas adaptaçôes necessárias, capacitação profissional, conscientização da deficiência, ensino de Braille, escrita alternativa, Comunicação Alternativa, desenvolvimento de técnicas e materiais pedagógicos, adequaçóes para mobilidade, entre outros (BRASIL, 2007). 
Para identificar as barreiras que podem dificultar a aprendizagem e a compreensão da mensagem transmitida graficamente, é fundamental o uso de instrumentos que auxiliem na avaliação da acessibilidade e orientem a respeito das adaptaçóes necessárias para eliminar os problemas encontrados.

Alguns estudos fornecem listas de verificação voltadas para a adequabilidade na transmissão de informações para a educação em Saúde (BERGUER, 2011), como o instrumento Suitability Assessment of Materials (SAM), desenvolvido e validado em 1996 por Doak e colaboradores, e traduzido em 2015 para o português (SOUSA; TURRINI; POVEDA, 2015). Outro exemplo é o Guideline on the readability of the label and package leaflet of medicinal products for human use, que orienta na transmissão de conceitos e termos técnicos sobre medicamentos ou procedimentos de saúde de forma acessível (EUROPEAN COMMISSION, 2009). Ambos abordam aspectos como a adequação do conteúdo ao cliente, apresentação do texto, ilustração e adaptação cultural.

Outros documentos oferecem avaliação de Objetos de Aprendizagem que auxiliam o professor na análise desses recursos digitais, conforme critérios e concepçóes pedagógicas, bem como na exibição do material e conteúdo aos alunos (REATEGUI; BOFF; FINCO, 2010).

O Guia para Desenho Universal para Aprendizagem - DUA (CAST, 2011) inclui três princípios básicos para a acessibilidade na educação, buscando dessa forma criar estratégias, materiais e programas que sejam acessíveis para todos: 1) oferecer diferentes opçóes de apresentação do material, para que o aluno possa escolher o que mais atende as suas necessidades, para facilitar a sua compreensão; 2) oferecer diversas possibilidades de ação e expressão, de modo que o aluno tenha oportunidade de expressar o que foi aprendido; 3) oferecer variadas formas para promover o engajamento na atividade, que estimule o aluno a se interessar pela aprendizagem.

Para a elaboração de materiais de fácil acesso, que favoreçam a aquisição de conhecimento de crianças com necessidades específicas, relacionadas ou não a uma deficiência, é preciso que haja a prestação de serviço por profissionais habilitados (ROCHA; SANT'ANNA; PELOSI, 2017). Um desses profissionais é o terapeuta ocupacional, que é capaz de analisar as necessidades e potencialidades do estudante, a demanda da atividade e o contexto no qual ela está inserida. Ele compreende o processo de ensino-aprendizagem com foco no interesse e nas particularidades do aluno (ROSA et al., 2014), e contribui para o desenvolvimento de açóes para identificar e reduzir as barreiras que dificultam sua inclusão (BARTALOTTI, 2011).

Contudo, o terapeuta ocupacional não atua com foco apenas no aluno, mas também no professor, na escola e no sistema educacional (LOURENÇO; CID, 2010), fortalecendo, assim, o potencial de ambos para açóes desenvolvidas nessa área (ROCHA; LUIZ; ZULIAN, 2003).

Em suas práticas, tem como propósito melhorar ou possibilitar a participação em papéis, hábitos e rotinas nos diversos ambientes como a casa, a escola, o local de trabalho, a comunidade e outros lugares, e atua por meio de mudanças e adaptaçóes realizadas no ambiente, objetos ou no processo da atividade. Suas açóes consideram sempre os fatores pessoais do sujeito, suas habilidades, os significados culturais e sociais (AOTA, 2015). 
Finalmente, para favorecer o desenvolvimento da criança, é necessário acreditar no seu potencial, abstendo-se de qualquer estigma e preconceito sobre sua capacidade. Os envolvidos no processo de aprendizagem das crianças com síndrome de Down têm a responsabilidade de elaborar estratégias no currículo escolar, práticas pedagógicas, interação, comunicação e socialização que facilitem a plena inclusão no processo educacional da criança (LAMÔNICA; FERREIRA-VASQUES, 2015).

Este estudo teve como objetivo analisar a acessibilidade das atividades gráficas aplicadas às crianças com síndrome de Down nos atendimentos terapêuticos ocupacionais, que ocorreram em uma Brinquedoteca Terapêutica, no período de um semestre.

\section{Método}

Trata-se de uma pesquisa aplicada, descritiva, com abordagem quantitativa, aprovada pelo Comitê de Ética em Pesquisa, sob o parecer 1.149.757 de 9/6/2015, com o CAAE: 45602715.6.0000.5264.

Para a pesquisa, foram selecionadas e analisadas 278 atividades utilizadas no atendimento a 24 crianças com síndrome de Down, com idades entre 2 e 13 anos, acompanhadas por terapeutas ocupacionais na Brinquedoteca Terapêutica de um hospital universitário da Região Sudeste do país. Para analisá-las, foi elaborado um protocolo de identificação das características gerais dos materiais gráficos.

As crianças estavam organizadas em cinco grupos, com objetivos terapêuticos semelhantes, compostos, em média, por cinco crianças da mesma faixa etária. Não havia crianças com 5 anos de idade no período avaliado. Para a análise dos dados, foram incluídos todos os materiais gráficos desenvolvidos na brinquedoteca e encaminhados para casa no período de fevereiro a julho de 2015. Foram excluídas as atividades gráficas elaboradas que não tinham sido respondidas pelas crianças.

Destaca-se que o Protocolo de Análise da Acessibilidade de Atividades Gráficas utilizado foi construído pelas autoras, com base em suas experiências, assim como na literatura científica. $\mathrm{O}$ protocolo teve por base as diretrizes de documentos como as normas da Associação Brasileira de Normas Técnicas e as determinaçóes dos Centros de Controle e Prevenção de Doenças dos Estados Unidos (ABNT, 2004; CDC, 2009; BERGUER, 2011) e do Guideline on the readability of labelling and package leaflet of medicinal products for human use, que lista, em tópicos comentados, orientações para elaboração de textos informativos em Saúde (EUROPEAN COMMISSION, 2009).

Além disso, a criação do protocolo foi baseada em instrumentos como o Suitability Assessment of Materials (SAM) na versão em português, caracterizado por apresentar itens de verificação divididos em seis categorias, que abordam a compreensão do texto, ilustração, apresentação do material, motivação para leitura, adaptação cultural e de conteúdo, e utiliza uma escala numérica para pontuação que identifica barreiras na comunicação por escrito, com foco na educação em Saúde (SOUSA; TURRINI; POVEDA, 2015). Foi considerado, também, o instrumento para avaliação de Objetos de Aprendizagem, que verifica a adequabilidade do material digital em duas partes principais: identificação do conceito pedagógico e os aspectos 
tecnológicos, que incluem questóes sobre o funcionamento do sistema digital, e os de apresentação dos textos como fonte, contraste e ilustração (REATEGUI; BOFF; FINCO, 2010).

Após a etapa de construção e adequação do roteiro, realizou-se um teste-piloto em algumas atividades gráficas, com o objetivo de averiguar se todos os itens haviam sido contemplados. Em seguida, o protocolo foi avaliado e testado por quatro terapeutas ocupacionais consultores e pesquisadores da área da infância para realização dos ajustes necessários. Além disso, a avaliadora passou por treinamento e capacitação, referente à aplicação do protocolo.

O protocolo elaborado para a análise da acessibilidade de materiais gráficos possuía 44 itens, divididos em 3 categorias:

1) Características gerais - origem da atividade (disponível no portal; criada e impressa; feita à mão); tipo (ligar; assinalar; nomear; completar; com textura; de colagem; desenho com modelo; desenho livre; pintura e outros); exercícios grafomotores (formas, letras, números, nome, e outros); de leitura e escrita (com apoio ou sem apoio de modelo, letras, sílabas, palavras monossílabas, dissílabas, trissílabas ou polissílabas com ou sem dificuldade ortográfica, frases, textos); de matemática (correspondência, comparação, classificação, sequência, seriação, inclusão, conservação, relação número e quantidade, escrita de números com ou sem apoio de modelo, soma, subtração, divisão, multiplicação, formas geométricas e noçôes matemáticas como grande e pequeno, igual e diferente, antes e depois etc.); e outros conceitos (ciências, geografia, história).

2) Análise da acessibilidade, considerando: características do papel (tamanho, cor, fosco ou com brilho e a qualidade de impressão); organização da folha (realizada apenas em uma folha, conteúdo com uma a três proposiçóes, sem enunciado, com um, dois ou mais enunciados); organização e pistas visuais (evita distratores e excesso de elementos, há espaços em branco para facilitar a visualização, informações dispostas na ordem sequencial das açôes que se deseja transmitir, conteúdo contextualizado com a cultura brasileira, presença de símbolos complementares como setas e sinais para orientar a resposta, locais indicados para a resposta, aproveitamento de toda a folha); legibilidade do texto com informaçóes para o enunciado e o corpo do trabalho (presença de texto no enunciado e no corpo da atividade); característica da fonte das letras para o enunciado e corpo do trabalho (fonte sem serifa, evita fontes com enfeite, a maior parte dos textos com letra de imprensa maiúscula, fonte acima de 16 pontos, letra com contraste de cores em relação ao papel); análise do texto escrito com informaçóes para o enunciado e corpo do trabalho (informação clara, simples, consistente, que evita ambiguidades, sem erro de conteúdo ou nas opçóes de resposta, usa palavras ou frases curtas, usa mais palavras sem dificuldades ortográficas, utiliza palavras e termos comumente empregados e define termos incomuns; a organização do texto facilita a compreensão, a informação principal está destacada em negrito ou sublinhada); análise dos desenhos, símbolos e fotografias em relação ao enunciado e corpo do trabalho (atividade apoiada com imagens, figuras claras que reforçam a informação, possibilidade de compreender o enunciado apenas observando os símbolos, imagens contextualizadas com a cultura brasileira, de alta resolução, e com contraste em relação ao papel).

3) Avaliação das respostas, considerando o material utilizado (recursos que exigem mais coordenação motora fina, como caneta, lápis ou lápis de cor, e menos coordenação, como 
tinta, giz de cera, colagem) e tipo de resposta (se foi respondida corretamente, se as letras e números estavam contidos no espaço reservado, adequação para açóes de circular, colar e pintar, conforme solicitação do enunciado).

Considerando os subitens, o protocolo contou com 95 perguntas no total. Destacase que todas as variáveis foram caracterizadas como sim e não.

Quando necessário, a análise considerou aspectos do corpo do trabalho e do enunciado, ou agregou subitens para a categoria.

Para a análise dos dados, foi construída uma planilha eletrônica, no programa Excel, e o banco de dados foi posteriormente exportado para o software Statistical Package for The Social Sciences - SPSS, versão 19.0.

Com a finalidade de alcançar os objetivos do estudo, foi feita a análise univariada descritiva, utilizando-se frequências absolutas e relativas para as variáveis categóricas, e medidas de tendência central (média ou mediana) para as variáveis quantitativas. Para comparar as variáveis categóricas com a ocorrência de respostas corretas, origem e tipo de atividade, foi realizada análise bivariada empregando-se teste qui-quadrado $(X)^{2}$, considerado um nível de significância de $p<0,05$ e intervalo de confiança (IC) de $95 \%$.

\section{Resultados}

\subsection{Distribuiçáo Das ATIVIDADES ANALISADAS}

Cada grupo desenvolveu um número variado de atividades gráficas, como mostra a Tabela 1. Estas estavam contextualizadas com temas e conceitos trabalhados nos momentos iniciais dos atendimentos, a partir do uso de jogos, brincadeiras e outras atividades. A análise do material foi realizada após a aplicação.

Tabela 1 - Distribuição das atividades analisadas.

\begin{tabular}{l|l|l|l|l}
\hline \multicolumn{1}{c|}{ Grupo } & \multicolumn{1}{|c|}{ Idade } & No de crianças & \multicolumn{1}{c}{ Objetivo } & \multicolumn{1}{c}{$\begin{array}{c}\text { Atividades } \\
\text { analisadas }\end{array}$} \\
\hline Grupo 1 & 2 a 4 anos & 6 crianças & $\begin{array}{l}\text { Brincar, estimulação de lingua- } \\
\text { gem e socializaçáo }\end{array}$ & 17 atividades \\
\hline Grupo 2 & 6 a 8 anos & 3 crianças & $\begin{array}{l}\text { Socializaçáo, conceitos, desenvol- } \\
\text { vimento de leitura e escrita }\end{array}$ & 41 atividades \\
\hline Grupo 3 & 8 a 10 anos & 4 crianças & $\begin{array}{l}\text { Desenvolvimento de leitura, } \\
\text { escrita e conceitos }\end{array}$ & 22 atividades \\
\hline Grupo 4 & 10 a 13 anos & 6 crianças & $\begin{array}{l}\text { Desenvolvimento de leitura, } \\
\text { escrita e conceitos }\end{array}$ & 144 atividades \\
\hline Grupo 5 & 10 a 13 anos & 5 crianças & $\begin{array}{l}\text { Desenvolvimento de leitura, } \\
\text { escrita e conceitos }\end{array}$ & 54 atividades \\
\hline
\end{tabular}

Fonte: elaboração própria. 


\subsection{CARACTERÍsticas gerais dA ATIVIDADE}

Nessa primeira categoria, foram identificadas as características mais gerais das atividades: a origem; o tipo; e conceitos trabalhados.

$\mathrm{Na}$ brinquedoteca, a origem dos materiais podia ser do depositório de atividades do projeto, portal na internet, $(43,9 \%)$, aqueles criados pelos terapeutas ou estagiários e impressos $(47,1 \%)$ ou feitos à mão $(10,1 \%)$. Os do portal foram identificados pela presença da logo do projeto ou notas no rodapé com informaçóes da Terapia Ocupacional.

A correlação entre a origem das atividades (retiradas do Portal Assistiva ou elaboradas pelos terapeutas ocupacionais, impressas ou feitas à mão) e os cinco diferentes grupos mostrou que a maior proporção das atividades havia sido retirada do Portal Assistiva e realizada com o grupo 4, de crianças de 10 a 13 anos (84,6\%; p < 0,001). Enquanto nos demais grupos, todas as atividades haviam sido elaboradas pelos terapeutas ocupacionais.

Ao longo do semestre, foram desenvolvidas atividades de completar $(46,4 \%)$, colagem (22,7\%), assinalar (22,7\%), ligar (12,6\%), pintar (6,1\%) e desenhar livremente (4,7\%), além daquelas com texturas $(2,2 \%)$ e outras $(2,1 \%)$, considerando que uma podia demandar mais de uma ação, como pintar e colar.

As atividades gráficas variaram em função do objetivo proposto e foram classificadas em "atividades grafomotoras", "atividades de aquisição de leitura e escrita", "atividades de matemática” e "outros conceitos".

As atividades grafomotoras (5\%) tinham o objetivo de favorecer o treino da grafia das letras, dos números e dos movimentos preparatórios para a escrita. Dentre as 14 identificadas, as mais frequentes foram a grafia das letras $(64,3 \%)$ e a dos números $(21,4 \%)$. Formas, nomes, movimentos foram usados em menos de $14,5 \%$ das atividades gráficas dessa categoria.

Em relação aos conteúdos mais trabalhados no material analisado, verificou-se que a maior parte correspondia a leitura e escrita (49,6\%), utilizando, preferencialmente, palavras dissílabas sem dificuldade ortográfica $(65,2 \%)$, letras $(44,2 \%)$ e palavras trissílabas sem dificuldade ortográfica $(39,1 \%)$.

A análise do material gráfico de matemática foi organizada, considerando os diferentes conceitos da área, e representou 46\% da amostra. Destacaram-se as atividades de correspondência $(40,6 \%)$, relação número e quantidade $(30,5 \%)$, comparação $(18,0 \%)$, noções matemáticas como tamanho, posição no espaço $(14,1 \%)$, soma $(12,5 \%)$, inclusão de classe $(8,6 \%)$, classificação $(8,6 \%)$ e sequência $(7,0 \%)$.

Foram encontrados poucos materiais que trabalhavam conceitos de ciências $(3,6 \%)$ e nenhum com conteúdo de história ou geografia.

\subsection{ANÁLISE DA ACESSIBILIDADE DA ATIVIDADE GRÁFICA}

A segunda categoria do protocolo analisou os elementos de acessibilidade do texto escrito e/ou com imagens. Buscou-se identificar as características da apresentaçáo do material, a forma como estava organizado na folha, as pistas visuais, contraste, tipo de papel, e o uso adequado dos espaços e imagens. 
Grande parte das atividades da brinquedoteca foi desenvolvida em papel A4 (96,8\%). Algumas foram elaboradas em papel branco (84,9\%) ou reciclado (15,1\%), e nenhuma em papel colorido. Todos os trabalhos utilizaram papel fosco.

Verificou-se que quase todos os materiais foram organizados em apenas uma folha $(97,5 \%)$, e continham um único enunciado (76,3\%). Parte do conjunto não tinha enunciado $(23,7 \%)$, e poucos tinham mais de um $(2,5 \%)$. A respeito da quantidade de proposiçóes por folha, a maioria foi organizada com uma ou duas por folha $(59,7 \%)$. A metade tinha espaço reservado para a resposta $(52,5 \%)$, porém poucas apresentaram elementos para orientá-la e direcioná-la $(6,8 \%)$.

Alguns materiais apresentavam logomarcas, contornos, enfeites e outros elementos que poderiam afetar a atenção do leitor, portanto, foi criado um item no protocolo para considerar essa característica.

As atividades apresentaram espaços em branco entre os elementos $(97,1 \%)$, evitando o excesso de elementos visuais no mesmo local (81,3\%). Pouco mais de um terço apresentou elementos distratores $(39,2 \%)$, e, em sua maioria, estavam relacionados à logomarca do patrocinador do projeto.

O aproveitamento dos espaços foi considerado como parte da organização e apresentação visual do material. Dentre o material analisado, 11,7\% apresentaram enunciado que ocupou uma parte significativa da folha, mais de 5 centímetros, reduzindo assim o espaço do corpo do trabalho. Neste ponto, a maioria estava adequada, e com bom aproveitamento da folha $(83,7 \%)$.

Em relação ao texto, é possível dizer que 214 atividades (77\%) tinham enunciado, e suas características mais comuns foram fonte sem serifa $(96,7 \%)$ e letra maiúscula $(98,1 \%)$.

No corpo do trabalho, 129 atividades $(46,4 \%)$ tinham texto escrito com as mesmas características encontradas no enunciado. Apresentaram fonte sem serifa $(82,9 \%)$ e letra apenas maiúscula (99,2\%). Não foram encontrados materiais com letra cursiva, em itálico, nem com letras enfeitadas no enunciado ou no corpo do trabalho, que poderiam confundir o leitor.

Em relação ao tamanho da fonte nos enunciados, os resultados mostraram que a maior parte estava acima de 16 pontos, e o das letras apresentava-se entre 18 e 24 pontos $(55,6 \%)$ ou acima de 26 pontos $(26,2 \%)$. No corpo do trabalho, $91,5 \%$ das letras tinham tamanho da fonte maior do que 26 pontos.

A maioria apresentou bom contraste no enunciado $(99,5 \%)$ e no corpo do trabalho $(99,2 \%)$.

Das 214 atividades com enunciado, o maior número ofereceu informação clara $(93,1 \%)$, com palavras curtas $(93,5 \%)$, sem dificuldade ortográfica $(58,4 \%)$ e palavras comumente utilizadas $(97,7 \%)$. As palavras incomuns apareceram em apenas 15 atividades, sendo que em metade delas as palavras foram explicadas. $\mathrm{O}$ texto foi organizado de maneira a facilitar a compreensão $(97,2 \%)$, apesar de poucos apresentarem destaque na informação principal $(6,1 \%)$. 
No corpo do trabalho, o resultado foi semelhante. Nas 129 atividades, prevaleceram informaçóes claras $(97,7 \%)$, com palavras comuns $(92,2 \%)$, curtas $(89,9 \%)$, sem dificuldade ortográfica $(78,3 \%)$, e com textos que facilitaram a compreensão $(90,7 \%)$. Contudo, poucas apresentaram destaque na informação principal (6,2\%).

Os enunciados auxiliados por imagens foram observados em 72 dos materiais analisados $(25,9 \%)$. Na maior parte destes, as imagens utilizadas foram claras e buscaram reforçar a informação $(54,2 \%)$, estavam contextualizadas com a cultura brasileira $(54,2 \%)$ e tinham boa resolução $(79,2 \%)$ e bom contraste $(83,3 \%)$.

O uso de imagens no corpo do trabalho foi observado em 204 atividades (73,4\%). Destas, um número significativo estava claramente apoiando a informação $(92,2 \%)$, contextualizadas com a cultura brasileira $(96,6 \%)$, com boa resolução $(66,2 \%)$, bom contraste $(64,7 \%)$ e possibilitavam a compreensão da informação apenas ao serem observadas $(65,2 \%)$.

\subsection{Avaliaçáo das Respostas}

A terceira categoria objetivou analisar as respostas das crianças nas atividades, considerando itens como o recurso utilizado, o tipo de resposta dada e o desempenho grafomotor.

Os materiais mais utilizados para as repostas foram aqueles que exigem mais coordenação motora fina: lápis preto $(36,7 \%)$, lápis de cor $(22,7 \%)$ e caneta hidrocor $(13,7 \%)$. Materiais que exigem menos destreza como elementos para a colagem $(24,5 \%)$, tinta $(0,4 \%)$ e giz de cera $(6,5 \%)$ foram menos empregados.

Foi possível avaliar as respostas das crianças em parte das atividades (77\%) e, destas, a maioria foi respondida corretamente $(79,4 \%)$ e com desempenho grafomotor adequado (85,0\%).

Em 64 atividades, não foi possível identificar se a resposta estava correta ou se o desempenho grafomotor foi adequado. Isto ocorreu pelo fato de elas não possuírem enunciado indicando qual era a sua proposta, e, também, por esta pesquisa ter avaliado os materiais gráficos após terem sido aplicados, não tendo sido possível a identificação da instrução do terapeuta.

Quanto às respostas corretas, verificou-se que os maiores percentuais estavam relacionados às atividades retiradas do Portal Assistiva $(81,8 \%)$, que eram de assinalar $(84,2 \%)$ e completar $(80,6 \%)$, Tabela 2. 
Tabela 2 - Distribuição da frequência das variáveis origem da atividade e modalidade de atividade, segundo ocorrência de respostas corretas, de atividades realizadas em uma brinquedoteca $(\mathrm{n}=214)$.

\begin{tabular}{|c|c|c|c|}
\hline \multirow[b]{2}{*}{ Variáveis } & \multicolumn{3}{|c|}{ Respostas corretas } \\
\hline & $\begin{array}{l}\text { Sim } \\
\mathrm{N}(\%)\end{array}$ & $\begin{array}{l}\text { Náo } \\
\text { N (\%) }\end{array}$ & $p^{*}$ \\
\hline \multicolumn{4}{|l|}{ Origem da Atividade } \\
\hline Atividade retirada do Portal Assistiva & $99(81,8 \%)$ & $22(18,2 \%)$ & \multirow[b]{2}{*}{0,326} \\
\hline $\begin{array}{l}\text { Atividade elaborada pelos terapeutas } \\
\text { impressa ou feita à mão }\end{array}$ & $71(76,3 \%)$ & $22(23,7 \%)$ & \\
\hline \multicolumn{4}{|l|}{ Ligar } \\
\hline Sim & $22(68,8 \%)$ & $10(31,3 \%)$ & \multirow{2}{*}{0,105} \\
\hline Não & $148(81,3 \%)$ & $34(18,7 \%)$ & \\
\hline \multicolumn{4}{|l|}{ Assinalar } \\
\hline Sim & $48(84,2 \%)$ & $9(15,8 \%)$ & \multirow{2}{*}{0,298} \\
\hline Não & $122(77,7 \%)$ & $35(22,3 \%)$ & \\
\hline \multicolumn{4}{|l|}{ Completar } \\
\hline Sim & $83(80,6 \%)$ & $20(19,4 \%)$ & \multirow[b]{2}{*}{0,690} \\
\hline Não & $87(78,4 \%)$ & $24(21,6 \%)$ & \\
\hline
\end{tabular}

$p^{*}<0,05$

Fonte: elaboração própria

A correlação entre a variável resposta correta e os diferentes grupos mostrou maior proporção das atividades respondidas corretamente pelo Grupo 4, de crianças de 10 a 13 anos (85,7\%), seguido do grupo 2, de crianças de 6 a 8 anos (76,2\%) e do Grupo 3, de crianças de 8 a 10 anos $(75,0 \%)(p=0,005)$.

$\mathrm{Na}$ comparação do tipo de atividade com os diferentes grupos, os resultados mostraram maior proporção de atividades de leitura e escrita no grupo 2, de crianças de 6 a 8 anos $(75,6 \%)(p<0,005)$ e de atividade de matemática no Grupo 4, de crianças de 10 a 13 anos $(62,5 \%)(p<0,005)$. E demonstraram, ainda, que o desempenho grafomotor foi adequado em quatro grupos, que compreendem crianças acima de 6 anos $(p<0,005)$.

\section{Discussão}

\subsection{Características da ATIVIDADE}

O grupo de 2 a 4 anos realizou poucos trabalhos gráficos. Os principais objetivos das intervençôes terapêuticas ocupacionais deste grupo envolveram a estimulação do brincar e o desenvolvimento da linguagem e da socialização. Os 17 trabalhos analisados tinham demandas de pintura, colagem e uso de texturas. 
Nos grupos de crianças de 6 a 13 anos, as atividades gráficas mostraram-se mais frequentes. Foram avaliados 261 materiais que estavam relacionados aos objetivos delineados pelos terapeutas ocupacionais para cada um dos grupos, e envolveram objetivos como o desenvolvimento da leitura e da escrita e de conceitos matemáticos. Muitos deles faziam referência a conceitos ou temas relacionados a jogos utilizados na brinquedoteca como "Pizzaria Maluca", "Pula Pirata", "Floresta Encantada"; "Explosão", entre outros.

Incluídas neste conjunto, havia as crianças do grupo 4 que participavam do Projeto TO Brincando com a Fono, uma ação interdisciplinar das áreas de Terapia Ocupacional, Fonoaudiologia e Pedagogia para a construção de atividades lúdicas, com o objetivo de desenvolver as habilidades de consciência fonológica como aliteração, rima, manipulação, transposição e segmentação silábica. Os profissionais deste projeto produziram um conjunto de atividades, baseadas na experiência do trabalho com este grupo, que foram postadas no Portal Assistiva (MOUSINHO et al., 2017).

O trabalho desenvolvido na brinquedoteca terapêutica, por terapeutas ocupacionais, teve como objetivo oferecer para a criança, por meio de atividades lúdicas, a oportunidade de desenvolver seu potencial e superar suas dificuldades específicas, brincando com jogos e materiais especialmente criados ou selecionados (GIMENES; TEIXEIRA, 2011). Este trabalho também se baseou na premissa de que é por meio da experiência do brincar que a criança explora o ambiente, interage com o mundo, influencia, modifica o espaço e aprende durante o processo (SANTOS; MARQUES; PFEIFER, 2006; MONTEIRO; CORREA, 2012).

Contudo, os usuários dessa brinquedoteca eram crianças com deficiência, e, por esta razão, os materiais utilizados foram adaptados para atender a demanda de sua clientela, com a simplificação de regras, escrita com símbolos e recursos de Comunicação Alternativa e outros recursos e estratégias de Tecnologia Assistiva. A intervenção incluiu, ainda, a comunicação e a orientação aos familiares, cuidadores e profissionais da escola.

Como descrito por Coelho e Rezende (2011) e Bartalotti (2011), na área de Terapia Ocupacional, o profissional promove a participação de crianças nas atividades realizando intervençóes diretamente com elas, por meio da estimulação de suas habilidades de desempenho; efetuando modificaçóes e adaptaçóes no espaço, nos materiais, ou brinquedos; e fazendo uso de recursos e estratégias para alcançar os objetivos identificados. Considera, também, o contexto, a família e a singularidade do sujeito na sua intervenção.

O papel do terapeuta ocupacional nesta circunstância foi o de tornar possível a participação dos sujeitos e promover a funcionalidade em áreas como o brincar e a educação, potencializando o papel da criança como estudante (BARTALOTTI, 2011; AOTA, 2015).

\subsection{ANÁlisE DA ACESSIBILIDADE}

As atividades avaliadas buscaram transmitir a informação de forma simples, objetiva e organizada, com o uso de palavras curtas e poucas dificuldades ortográficas, conforme menciona a literatura da área (CDC, 2009; BERGUER, 2011). Contudo, foi observado o emprego de algumas palavras que apresentavam dificuldade ortográfica nos enunciados, para transmitir as informações desejadas. 
É importante salientar que a organização e a apresentação da informação afetam o interesse do leitor. As informaçóes essenciais devem aparecer antes de qualquer outra, mantendo a sequência das açóes que se deseja transmitir, com destaques nas palavras-chave que fornecem pistas e contribuem para a memorização da ideia principal (CDC, 2009; BERGUER, 2011). No material analisado, não foi observado o destaque das palavras-chave, sendo este um dos pontos a ser considerado na elaboração de novas atividades.

A respeito da acessibilidade na formatação das palavras, as atividades estavam adequadas quanto ao tamanho das letras e contraste. $\mathrm{O}$ tamanho apropriado da fonte indicado pela literatura é acima de 12 pontos, para leitores sem alteração visual. Para leitores com baixa visão, é recomendada uma fonte acima de 14 pontos (CDC, 2009) ou de 16 pontos (ABNT, 2004). Com a finalidade de abranger a necessidade da maior parte das crianças foi considerado como ideal o tamanho das letras acima de 16 pontos, o qual foi superado na maioria das atividades.

O contraste das letras e imagens em relação à cor do papel impacta na visualização, e uma quantidade considerável das atividades respeitou essa orientação e foram criadas em papel branco, fosco, com letras pretas. Os altos contrastes são obtidos levando-se em conta a relação entre as cores preto e branco, azul e laranja, azul e amarelo, ou seja, aquelas opostas na palheta de cores. Cores próximas como amarelo e laranja criam materiais com baixo contraste (BERGUER, 2011).

Já sobre o tipo de fonte e uso de letras maiúsculas, os resultados divergiram de parte da literatura, que embasa o protocolo de avaliação de acessibilidade gráfica e orienta o uso de fonte com serifa e letras alternadas em maiúscula e minúscula (ABNT, 2004; CDC, 2009; BERGUER, 2011).

Neste sentido, seria natural afirmar que as atividades não estavam acessíveis, pois a maioria foi desenvolvida com letras sem serifa e palavras em letras maiúsculas. Assim, ao considerar as dificuldades de percepção e discriminação visual das letras por crianças com deficiência, este item precisa ser discutido de maneira mais abrangente. Apesar das palavras escritas com letra com serifa, como Times New Roman, e alternadas em maiúsculas e minúsculas estarem apropriadas para muitos leitores, podem não ser acessíveis quando tratamos de sujeitos com alteraçóes sensoriais ou perceptivas.

O estudo de Sciliar-Cabral (2013) descreve que o cérebro humano é capaz de identificar letras independentemente da variação de estilo, tamanho e fonte. Contudo, ele apresenta complexidade no que se refere à discriminação e à percepção das letras semelhantes, destacando que esta dificuldade está relacionada, principalmente, à direção na qual a letra é escrita, como nas letras voltadas para cima ou para baixo m/w, n/u, b/p, d/q, ou aquelas em que o traço se direciona para a direita ou para a esquerda b/d, p/q, sendo estas últimas mais complexas do que as primeiras.

Levando em conta estas informaçóes, é possível justificar a necessidade de mais investigações a respeito do tipo de fonte adequada para pessoas com alterações perceptivas. Se a dificuldade de aprendizado decorre, entre outros aspectos, da não identificação do sentido das letras, é legítimo considerar que para essas pessoas o material acessível ao aprendizado da leitura e escrita é aquele em que as palavras estão escritas com todas as letras em maiúscula, já que neste caso não há variação de direção em letras como $\mathrm{B}, \mathrm{D}$ ou $\mathrm{P}, \mathrm{Q}$.

A presença de elementos escritos ocorreu mais no enunciado, no qual as frases foram mais frequentes do que no corpo do trabalho, que teve prevalência de letras e palavras. 
A facilidade de leitura de um material é determinada pela clareza da informação, pela ausência de palavras ambíguas, por frases curtas, termos comumente utilizados e predominância de palavras com poucas sílabas, características que estavam presentes na grande maioria das atividades elaboradas (BERGUER, 2011). Em todos os casos, é fundamental que não haja erros que possam confundir o leitor.

No enunciado, algumas informações fizeram uso de símbolos para apoiá-las, mas a escolha das imagens para representar a mensagem não foi adequada, pois o resultado aponta que foi impossível compreender a informação apenas com a figura, apesar dos bons elementos visuais. Além disso, alguns enunciados apresentaram apenas uma imagem para dar apoio a um conjunto de palavras, dificultando a compreensão de toda a informação. As imagens estavam claras visualmente, mas não eram apropriadas para representar e transmitir a mensagem desejada.

Diferentemente do que ocorreu no enunciado, as imagens foram mais frequentes no corpo do trabalho, e mais numerosas em atividades de contagem de elementos.

Uma atividade com imagens e/ou símbolos adequados pode reforçar a informação transmitida, além de tornar o material mais atraente. É necessário que sejam claras, com boa resolução, alto contraste, poucos detalhes, e que não sejam usadas apenas para decoração (CDC, 2009; BERGUER, 2011), o que foi pouco frequente no presente estudo.

A cor e o contraste são elementos visuais importantes no conjunto dos aspectos de acessibilidade das atividades gráficas. Durante a análise, foi observado que algumas imagens perdem o sentido se forem impressas em preto e branco, e outras se tornam menos atraentes, dependendo da proposta da atividade. Pouco mais da metade das atividades foram coloridas, outras foram impressas em escalas de cinza, mas, ainda assim, dentre estas, não foram encontradas atividades em preto e branco quando a cor era fundamental para a realização e compreensão da tarefa.

Informações visuais podem não fazer sentido para crianças com alterações de visão mas podem ser acessíveis para pessoas com alteraçôes cognitivas e auditivas, da mesma forma que as informações auditivas podem limitar o acesso para algumas pessoas. Por esta razão, para que uma informação seja acessível a todos os indivíduos, ela deve ser transmitida por meio de diversos recursos e estratégias (CAST, 2011).

As atividades que apresentaram enunciados foram organizadas apenas com um enunciado, na maior parte do material analisado, e com uma única atividade por folha.

Segundo a literatura que embasou o protocolo de análise, os textos são acessíveis quando transmitem a informação por etapas, mas é preferível que uma ideia esteja completa na mesma folha, para evitar que o leitor precise retornar à página anterior no meio da informação, o que exige mais atenção e memória (CDC, 2009).

Estes aspectos tornam-se ainda mais relevantes quando as atividades gráficas são desenvolvidas para crianças com síndrome de Down que apresentam alteraçóes cognitivas (BISSOTO, 2005; SILVA; KLEINHANS, 2006).

Quanto à organização da folha, na maioria das vezes os espaços foram bem aproveitados e os elementos bem distribuídos. Entretanto, em alguns casos, o enunciado ocupou um espaço excessivo, reduzindo, assim, o local para o corpo da atividade. 
Um texto com poucos elementos e com espaços em branco entre eles auxilia a compreensão, além de ser mais atraente do que uma atividade com excesso de informaçóes visuais que desestimule o leitor (CDC, 2009).

Outro elemento importante para a compreensão de uma informação é a presença de pistas visuais (BERGUER, 2011), que podem ser oferecidas de diversas maneiras. Nesta análise, foi considerada a presença de símbolos ou figuras para orientar a direção das atividades e espaços reservados para resposta. No entanto, os elementos com o objetivo de informar ou orientar podem ser distratores, se o leitor não compreender ou não estiver familiarizado com seu significado (CAST, 2011).

Conhecer previamente as características, a habilidade e o contexto do sujeito pode ser uma forma de reduzir a barreira causada pela presença de elementos desconhecidos (CDC, 2009).

Como as atividades gráficas avaliadas foram elaboradas com elementos comuns às crianças de diferentes idades, já era esperado que aquelas com elementos semânticos de orientação estivessem contextualizadas culturalmente, como aponta o resultado.

\subsection{Avaliaçáo das respostas}

Nesta categoria, foi possível avaliar $77 \%$ das atividades realizadas. Todas se mostraram acessíveis e adequadas ao nível de desenvolvimento das crianças atendidas. Os espaços para as respostas estavam compatíveis com a possibilidade grafomotora dos participantes, e estes foram estimulados a utilizar recursos que exigiam mais coordenação motora fina.

As respostas corretas foram encontradas em maior proporção nas atividades retiradas do Portal Assistiva, assim como na correlação das respostas corretas com as atividades de assinalar circulando, fazendo um $\mathrm{X}$, ou pintando a resposta, e nas atividades de completar com figuras, números, letras, sílabas, palavras ou frases. As atividades do Portal Assistiva foram desenvolvidas por uma equipe interdisciplinar, composta por profissionais das áreas de Terapia Ocupacional, Fonoaudiologia e Pedagogia que trabalhavam no Projeto TO Brincando com a Fono, cujo objetivo era o desenvolvimento de jogos, brincadeiras e atividades acessíveis para crianças com deficiência (MOUSINHO et al., 2017).

A partir da análise das atividades, verificou-se que as mais trabalhadas na brinquedoteca terapêutica estavam relacionadas aos objetivos traçados pelos terapeutas ocupacionais para cada um dos grupos atendidos, e que a atuação desses profissionais na elaboração e escolha das atividades gráficas foi fundamental para reduzir as barreiras que impedem a participação das crianças.

Faz parte das responsabilidades do terapeuta ocupacional avaliar a necessidade de a criança participar da atividade, e isso inclui os objetos essenciais, suas propriedades, as demandas sociais e de espaço, a sequência que deve ser seguida, o tempo e as açóes requeridas, além das funçóes e estruturas do corpo fundamentais (AOTA, 2010).

A análise das atividades compreende um processo lógico, que identifica as suas características por meio de um exame detalhado de seus componentes específicos (PEDRAL; BASTOS, 2013), sendo essa uma ação primordial no trabalho do terapeuta ocupacional. 


\section{Conclusấo}

A acessibilidade de atividades gráficas é, sem dúvida, um tema de extrema relevância para profissionais das áreas de Saúde e Educação que trabalham com crianças com deficiência. Materiais mal elaborados, inadequados quanto ao tipo de papel, fonte e tamanho da letra, com uso de imagens e pouco contraste ou não relacionadas ao contexto cultural da criança, com textos complexos e muitos elementos, representam barreiras para a participação dessas crianças em diferentes contextos.

Nesta pesquisa, as atividades mostraram-se acessíveis, considerando-se a maior parte dos elementos verificados. A apresentação visual do material, a organização do conteúdo, o nível de leitura e o uso de elementos para transmitir informaçóes estavam adequados. Os pontos que necessitam ser aprimorados incluem a escrita com símbolos, com a utilização de imagens mais representativas, o uso de elementos para direcionar o local da resposta e o destaque das palavras-chave dos enunciados.

Este estudo teve como limitação outros elementos referentes à aplicação da atividade que pudessem influenciar na acessibilidade, como a mediação, a iluminação e fatores emocionais da criança.

No entanto, apesar disto, espera-se que os resultados produzidos favoreçam a troca de conhecimentos em relação à facilidade de acesso a material gráfico, que auxilie os profissionais no processo de elaboração de atividades acessíveis, e direcione para o desenvolvimento de outras pesquisas com diferentes abordagens sobre esta temática, assim como com a população envolvida.

Além disso, é imprescindível que novos estudos possam investigar se a utilização de materiais acessíveis reduz o nível de assistência necessária para a realização das tarefas.

\section{REFERÊNCIAS}

AMERICAN OCCUPATIONAL THERAPY ASSOCIATION (AOTA). Estrutura da prática da terapia ocupacional: domínio e processo. 2. ed. Revista Triângulo: Ensino, Pesquisa e Extensão, Uberaba, v.3. n.2, p.57-147, jul.-dez. 2010. Disponível em: <http://www.uftm.edu.br/revistaeletronica/index. php/revistatriangulo/article/view/150/177>. Acesso em: 16 fev. 2016.

AMERICAN OCCUPATIONAL THERAPY ASSOCIATION (AOTA). Estrutura da prática da Terapia Ocupacional: domínio e processo. 3. ed. Revista de Terapia Ocupacional da Universidade de Sáo Paulo, São Paulo, v.26, n. esp., p.1-49, 2015. Disponível em: <http://www.revistas.usp.br/rto/article/ view/97496/96423>. Acesso em: 16 fev. 2016.

ASSOCIAÇÃO BRASILEIRA DE NORMAS TÉCNICAS (ABNT). ABNT NBR 9050:

Acessibilidade a edificaçóes, mobiliário, espaços e equipamentos urbanos. 2. ed. Rio de Janeiro, 2004.

ASSOCIAÇÃO BRASILEIRA DE NORMAS TÉCNICAS (ABNT). ABNT NBR 15599:

acessibilidade - comunicação na prestação de serviços. Rio de Janeiro, 2008.

BARTALOTTI, C.C. Deficiência mental. In: CAVALCANTI, A.; GALVÃO, C. Terapia ocupacional: fundamentaçâo e prática. Rio de Janeiro: Guanabara Koogan, 2011. Cap. 31, p.295-98.

BERGUER, S. Orientação do cliente. In: WILLARD, H.S.; SPACKMAN, C.S. Terapia ocupacional. Rio de Janeiro: Guanabara Koogan, 2011. Cap.41, p.424-32. 
BISSOTO, M.L. Desenvolvimento cognitivo e o processo de aprendizagem do portador de síndrome de Down: revendo concepçóes e perspectivas educacionais. Ciência e Cogniçâo, v.4, p.80-8, mar, 2005. Disponível em: <http:/www.cienciasecognicao.org/pdf/m11526.pdf>. Acesso em: 16 fev. 2016.

BRASIL. Presidência da República. Casa Civil. Lei no 13.146, de 6 de julho de 2015. Institui a Lei Brasileira de Inclusão da Pessoa com Deficiência (Estatuto da Pessoa com Deficiência). Disponível em: <http://www. planalto.gov.br/ccivil_03/_Ato2015-2018/2015/Lei/L13146.htm>. Acesso em: 6 maio 2016.

BRASIL. Secretaria Especial dos Direitos Humanos. Convenção sobre os direitos das pessoas com deficiência. 2007. Disponível em: <http://portal.mec.gov.br/index.php?option=com_ docman\&view=download\&alias=424-cartilha-c\&category_slug=documentos-pdf\&Itemid=30192> . Acesso em: 26 abr. 2016.

CALEGARI, E.P.; SILVA, R.S. da; SILVA, R.P. da. Design institucional e design universal para a aprendizagem: uma relação que visa obter melhorias na aprendizagem. Revista de designer, educação, sociedade e sustentabilidade, v.5, 2014. Disponível em: <http://www.lume.ufrgs.br/bitstream/ handle/10183/110356/000948864.pdf?sequence=1>. Acesso em: 6 maio 2016.

CENTER FOR APPLIED SPECIAL TECHNOLOGY (CAST). Universal design for learning guidelines: version 2.0. Wakefield, MA: Author, 2011. Disponível em: <http://www.udlcenter.org/ aboutudl/udlguidelines/principle1>. Acesso em: 26 maio 2016.

CENTER FOR DISEASE CONTROL AND PREVENTION (CDC). Simply put: a guide for creating easy-to-understand materials. 2009. Disponível em: <http://www.cdc.gov/helathliteracy/pdf/ Simply_Put.pdf >. Acesso em: 3 maio 2016.

COELHO, Z.A.C.; REZENDE, M.B. Atraso no desenvolvimento. In: CAVALCANTI, A.; GALVÃO, C. Terapia ocupacional: fundamentação e prática. Rio de Janeiro: Guanabara Koogan, 2011. Cap.32. p.299-305.

EUROPEAN COMMISSION ENTERPRISE AND INDUSTRY DIRECTORATEGENERAL. Guideline on the readability of labelling and package leaflet of medicine products for human use: revision 1. 2009. Disponível em: <http://ec.europa.eu/health/files/eudralex/vol-2/c/2009_01_12_ readability_guideline_final_en.pdf>. Acesso em: 23 jun. 2016.

GIMENES, B.P.; TEIXEIRA, S.R.O. Tipos de brinquedoteca. In: GIMENES, B.P.; TEIXEIRA, S.R.O. Brinquedoteca: manual em educação. São Paulo: Cortez, 2011. Cap.4. p.163.

LAMÔNICA, D.A.C.; FERREIRA-VASQUES, A.T. Habilidade comunicativas e lexicais de crianças com Síndrome de Down: reflexôes para inclusão escolar. Revista Cefac, v.17, n.5, p.1475-82, 2015. Disponível em: $<$ http://www.scielo.br/pdf/rcefac/v17n5/1982-0216-rcefac-17-05-01475.pdf >. Acesso em: 26 maio 2016.

LOURENÇO, G.F.; CID, M.F. Possibilidades de ação do terapeuta ocupacional na educação infantil: congruência com a proposta da educação inclusiva. Cadernos de Terapia Ocupacional da UFSCar, São Carlos, v.18, n.2, p.169-79, 2010. Disponível em: <http://www.cadernosdeterapiaocupacional.ufscar. br/index.php/cadernos/article/view/352/283>. Acesso em: 3 maio 2016.

MONTEIRO, L.S.; CORRÊA, V.A.C. Reflexôes sobre o brincar, a brinquedoteca e o processo de hospitalização. Revista Paraense de Medicina, v.26, n.3, 2012. Disponível em: <http://files.bvs.br/ upload/S/0101-5907/2012/v26n3/a3321.pdf>. Acesso em: 16 jun. 2016.

MOUSINHO, R. et al. Desenho Universal de Aprendizagem: jogos educativos com foco no desenvolvimento inicial da leitura. In: PEDRO, W. (Org.). Guia prático de neuroeducação. Rio de Janeiro: Wak Editora, 2017. Cap.4, p.125-45. 
PEDRAL, C.; BASTOS, P.M.M. Terapia ocupacional: metodologia e prática. 2. ed. Rio de Janeiro: Rubio, 2013.

REATEGUI, E.; BOFF, E.; FINCO, M.D. Proposta de diretrizes para avaliação de objetos de aprendizagem considerando aspectos pedagógicos e técnicos. Revista Renote: novas tecnologias na educação, v.8, n,3, 2010. Disponível em: <http://seer.ufrgs.br/index.php/renote/article/ view/18066/10653>. Acesso em: 23 jun. 2016.

ROCHA, A.N.D.C.; SANT’ANNA, M.M.M.; PELOSI, M.B. Terapia ocupacional: açóes colaborativas no contexto escolar. In: OLIVEIRA, J.P. et al. (Org.). Desenvolvimento Infantil, Escola e Inclusão: açóes pedagógicas e intersetoriais. Curitiba: CRV, 2017. Cap.7. p.141-60.

ROCHA, E.F.; LUIZ, A.; ZULIAN, M.A.R. Reflexôes sobre as possíveis contribuições da terapia ocupacional nos processos de inclusão escolar. Revista de Terapia Ocupacional da Universidade de São Paulo, v.14, n.2, p.72-78, 2003. Disponível em: <http://www.revistas.usp.br/rto/article/ view/13919/15737>. Acesso em: 16 jun. 2016.

ROSA, I.C.D. et al. Terapia ocupacional i educacion inclusiva: aspectos relacionados al desempeño ocupacional de personas con discapacidad. Revista Chilena de Terapia Ocupacional, v.14, n.1, p.12331, 2014. Disponível em: <http://www.revistaterapiaocupacional.uchile.cl/index.php/RTO/article/ viewFile/32397/34190>. Acesso em: 18 jun. 2016.

SANTOS, C.A.; MARQUES, E.M.; PFEIFER, L.I. A brinquedoteca sob a visão da terapia ocupacional: diferentes contextos. Cadernos de Terapia Ocupacional da UFSCar, 2006, v.14, n.2. Disponível em: <http://www.cadernosdeterapiaocupacional.ufscar.br/index.php/cadernos/article/ view/158/114>. Acesso em: 16 jun. 2016.

SCILIAR-CABRAL, L. Avanços das neurociências para a alfabetização e a leitura. Letras de Hoje, Porto Alegre, v.48, n.3, p 277-82, 2013. Disponível em: <http://revistaseletronicas.pucrs.br/ojs/index.php/ fale/article/view/12634>. Acesso em: 14 jun. 2016.

SILVA, M.D.F. M.C.; KLEINHANS, A.C.D.S. Processos cognitivos e plasticidade cerebral na síndrome de Down. Revista Brasileira de Educação Especial, Marília, v.12, n.1, p.123-38, 2006. Disponível em: <http://www.scielo.br/scielo.php?script=sci_ arttext\&pid=S1413-65382006000100009>. Acesso em: 26 maio 2016.

SOUSA, C.S.; TURRINI, R.N.T.; POVEDA, V.B. Tradução e adaptação do instrumento "suitability assessment of materials" (SAM) para o português. Revista de Enfermagem da UFPE on line, Recife, v.9, n.5, p.7854-7861, 2015. Disponível em: <http://www.revista.ufpe.br/revistaenfermagem/index.php/ revista/article/view/6766>. Acesso em: 17 jun. 2016.

SOUZA, M.C.D.; GOMES, C. Neurociência e o déficit intelectual: aportes para ação pedagógica. Revista Psicopedagogia, v.32, n.97, p.104-114, 2015. Disponível em: <http://pepsic.bvsalud.org/scielo. php?script=sci_arttext\&pid=S0103-84862015000100011>. Acesso em: 18 jun. 2016.

Recebido em: 05/05/2017

Reformulado em: 18/11/2017

Aprovado em: 07/12/2017 
BORGES. A.L.E. et al. 